\title{
Effect of pressure variation on the efficiency of supercritical fluid extraction of wild carrot (Daucus carota subsp. maritimus) extracts
}

\author{
Siwar Majdoub ${ }^{\mathrm{a}}$, Ridha El Mokni ${ }^{\mathrm{b}, \mathrm{c}, \mathrm{d}}$, Aliev Aslan Muradalievich ${ }^{\mathrm{e}, \mathrm{f}}$, Alessandra Piras $^{g}$, \\ Silvia Porcedda ${ }^{g}$, Saoussen Hammami ${ }^{\text {a,* }}$ \\ ${ }^{a}$ Research Unit 13ES63, Applied Chemistry and Environment, Monastir University, Faculty of Sciences of Monastir, Monastir 5000, University of Monastir, Tunisia \\ ${ }^{\mathrm{b}}$ Department of Life Sciences, Laboratory of Botany and Plant Ecology, Faculty of Sciences of Bizerta, Jarzouna-7021, Bizerta, University of Carthage, Tunisia \\ ${ }^{\mathrm{c}}$ Department Pharmaceutical Sciences "A", Laboratory of Botany, Cryptogamy and Plant Biology, Faculty of Pharmacy of Monastir, BP 207, Avenue Avicenna-5000, \\ University of Monastir, Tunisia \\ ${ }^{\mathrm{d}}$ Department of Silvo-Pastoral Resources, Laboratory of Silvo-Pastoral Resources, Silvo-Pastoral Institute of Tabarka, BP. 345, Tabarka 8110, University of Jendouba, \\ Tunisia \\ ${ }^{\mathrm{e}}$ Mountain Botanical Garden DSC RAS, Yaragskogo Street, 75, Makhachkala 367030, Russia \\ ${ }^{\mathrm{f}}$ Institute of Physics DSC RAS, Yaragskogo Street, 94, Makhachkala 367003, Russia \\ ${ }^{g}$ Department of Chemical and Geological Science, University of Cagliari, Cittadella Universitaria di Monserrato, S.P. Monserrato-Sestu km 0,700, 09042 Monserrato, Italy
}

\section{A R T I C L E I N F O}

\section{Keywords:}

Daucus carota subsp. maritimus

Supercritical carbon dioxide extraction

Hydrodistillation

Geranyl acetate

\begin{abstract}
A B S T R A C T
The present study was conducted to check the comparative qualities of essential oils prepared by hydrodistillation (HD) and supercritical fluid techniques. It constitutes the first attempt to investigate the chemical composition of Daucus carota subsp. maritimus extracts using supercritical fluid technology (SFE) as an environmentally clean innovative method of extraction. The effect of pressure on the nature of extractable substances from wild carrot has been performed at a constant temperature of $50{ }^{\circ} \mathrm{C}$ and two different pressures ( 100 and 300 bar). The experimental results showed that pressure had a significant enhancing effect on the fluid transport properties and therefore on yield values. The extraction yield increases from 1.167 to $2.986 \%$ while increasing pressure. The chemical compositions of the essential oils prepared by HD and SFE were analyzed on the basis of gas chromatography-mass spectroscopy (GC-MS). Thus, we noticed that all analyzed samples were enriched in geranyl acetate and $\beta$-bisabolene, and that the quantities of different identified substances were extremely sensitive to the extraction method and to the pressure variation in case of SFE.
\end{abstract}

\section{Introduction}

The use of essential oils of aromatic plants and spices dates back thousands of years, since they are made up of mixtures of volatile secondary metabolites rapidly absorbed by the body inducing a wide variety of benefits such as relieving the symptoms of insomnia, headaches and asthma. Many essences such those of lemon and rosemary are able to improve the immune system and relieve stress [1]. Several scientific investigators indicated that the chemicals makeup, the chemotypes and therefore, the biological properties depends, among other various conditions, on the variable extraction methods [2]. It is important to mention that the traditional techniques, as hydrodistillation, suffer from many drawbacks including low yield, losses of volatile compounds, long extraction times, degradation of unsaturated constituents and are known to be energy intensive methods [3]. In this sense, the extraction of unadulterated essential oils is required for clinical use [4]. Supercritical fluid extraction (SFE) technology, suggested as an innovative and clean extraction technique with several advantages, has progressed an increasing attention [5]. Supercritical carbon dioxide is the most commonly used because it is a safe, nonflammable, inexpensive, inert, odorless, colorless, tasteless, nontoxic, readily available solvent and of low critical pressure ( 74 bar) and temperature $\left(32^{\circ} \mathrm{C}\right)$ [6]. The supercritical fluid properties such as temperature and pressure are considered relatively low to facilitate the high selectivity of extracting various types of compounds, even those thermally unstable [7]. Supercritical fluid was first carried by Zosel in 1970 out at the Max Plank, Institute, to extract caffeine from coffee beans. Since then, numerous studies have sought the applicability of this new technology for the extraction of essential oils from different kinds of aromatic plants [2].

Nowadays, the interests for plants from the Apiaceae family are diversified more and more, where they are utilized commercially as

\footnotetext{
* Corresponding author.

E-mail address: h_saoussen@yahoo.fr (S. Hammami).
} 
vegetables, spices or drugs because of their richness on useful secondary metabolites [8]. Carrot, the main species belonging to this family, is like many others ((e. g., onions, fennel, tomatoes and potatoes), the most commonly consumed vegetable worldwide. Carrot is nutritionally important since it is considered as an excellent source of provitamin A, carotenoids, vitamins $\mathrm{C}, \mathrm{D}, \mathrm{E}, \mathrm{K}, \mathrm{B}_{1}, \mathrm{~B}_{6}$, biotin and minerals [9]. Up to now, it occupies a privileged status thanks to their nutritional aspects as a very powerful root vegetable utilized in soup, salad, cakes and juice [9]. In addition to their nutritional values, carrots are used in traditional herbal medicine due to its antilipemic, stomachic, hypotensive, carminative and diuretic properties [10]. Interestingly, carrot seed essential oil is extensively used as a flavoring agent in food products and as a fragrance in perfumes, soaps and cosmetics [11] because of its anthelmintic, antiseptic, diuretic, hepatic, stimulant and tonic properties [12]. Moreover, it has been reported that the wild carrot root is edible while young, but quickly becomes too woody to consume [13]. Those pleasant nutritional and pharmacological properties motivated us to investigate a comparison of the effect of both conventional hydrodistillation and innovative supercritical fluid extraction on the yield and chemical composition of the essential oils from wild carrot, Daucus carota subsp. maritimus. According to the current literature, the essential oil from wild $D$. carota has been found to contain many compounds. Carotol, geranyl acetate, sabinene, $\alpha$-pinene, are the most frequently encountered $[13,14]$. D. carota (subspecies not specified) has been also used in folk Tunisian medicine in the case of nephritic colic because of its carminative, aperitive, emmenagogue and diuretic properties [15]. Furthermore, this plant has been used as remedy for the treatment of cutaneous infections and has reputation for being antidiarrheal [15]. According to Alapetite [16], D. carota can be divided into three subspecies, viz., carota, maximus, and maritimus. Interestingly, the flowers and roots essential oils from Tunisian subspecies maritimus possesses interesting antibacterial activity against Gram (+) and Gram (-) bacteria. Based on the literature, the supercritical carbon dioxide extraction of carrot fruits essential oil showed that Serbian D. carota L. (subspecies not specified), is chiefly composed of carotol (30.3\%) [17]. Moreover, despite only one study which reported the extraction of essential oil from $D$. carota subsp. maritimus by hydrodistillation [15], no report have been published on identifying the essential oil chemical composition from aerial parts of this medicinal subspecies prepared by supercritical carbon dioxide methodology neither in Tunisia nor in other countries. In this context, and continuing our research on the chemical characterization of Tunisian Daucus genus [18,19], the present work is the first study on the chemical composition of $D$. carota subsp. maritimus volatile oils extracted by supercritical fluid technique with an emphasis on the effects of various sample preparation and extraction parameters on the yield and characteristics of the oils.

\section{Materials and methods}

\subsection{Plant material}

The aerial parts of $D$. carota subsp. maritimus were gathered during the flowering/fruiting stage from CE of Tunisia (Monastir) in July 2018. Taxonomical identity was assigned by Ridha El Mokni, a teacher-researcher in Botany, Cryptogamy and Plant Biology in the Faculty of Pharmacy of Monastir, Tunisia, where some voucher specimens have been deposited. Herbal parts were air-dried at ambient temperature in the shade and mixed well. Immediately prior to SFE, the sample was ground in a blender to produce powder.

\subsection{Raw material}

The supercritical extraction was carried out using $\mathrm{CO}_{2}$ of $99.9 \%$ in purity. Immediately before load the raw material into an extractor that was grinded to the sizes of $0.3-0.5 \mathrm{~mm}$ and the humidity level is defined to be $9.7(\mathrm{w} / \mathrm{w})$.

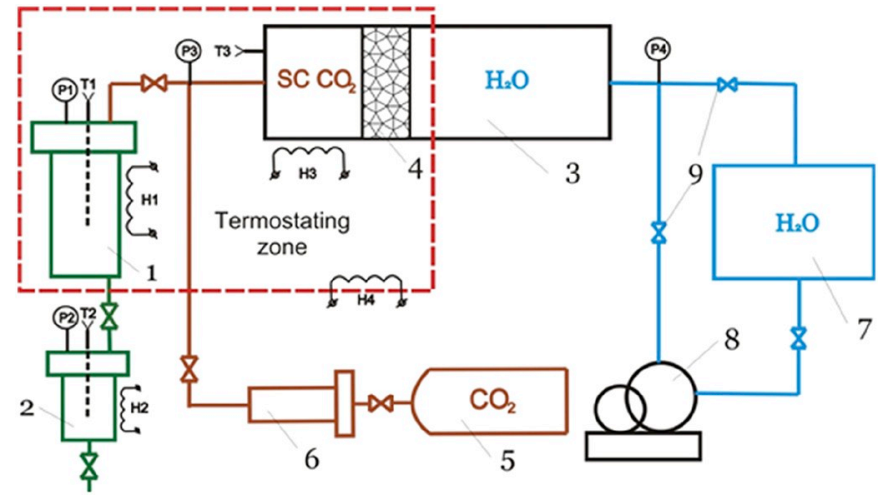

Fig. 1. Circuit diagram of the experimental plant for extraction with supercritical $\mathrm{CO}_{2}$ : (1) extractor, (2) separator, (3) power cylinder, (4) separating plunger, (5) cylinder with $\mathrm{CO}_{2}$, (6) filter for $\mathrm{CO}_{2}$ clearing, (7) reservoir with distilled water, (8) dosing high pressure pump, and (9) valves, P1, P2, P3, and $\mathrm{P} 4$ are the pressure transducers; $\mathrm{T} 1, \mathrm{~T} 2$, and $\mathrm{T} 3$ are the temperature transducers; $\mathrm{H} 1, \mathrm{H} 2, \mathrm{H} 3$, and $\mathrm{H} 4$ are heaters.

\subsection{Supercritical fluid extraction}

The measurements were made through the use of an experimental $\mathrm{CO}_{2}$ apparatus (Fig. 1) $[19,20]$. The apparatus provides an opportunity to make complex researches of extracting processes at pressures up to $400 \mathrm{bar}$ and temperature intervals from 25 to $100^{\circ} \mathrm{C}$ with the maximum flow of supercritical fluid of 1.7 ( \pm 0.05$) \mathrm{kg} / \mathrm{h}$. Raw material grinded $(170 \mathrm{~g})$ is loaded into a cylindrical extractor of $1 \mathrm{~L}(70 \mathrm{~mm}$ in inside diameter and $260 \mathrm{~mm}$ internal height) in volume and substances are extracted at a pressure of $100 \mathrm{bar}$ and a temperature of $50{ }^{\circ} \mathrm{C}$. Obtained extract is taken out. Next, we obtain an extract once again from the same portion of raw material at 300 bar and $50{ }^{\circ} \mathrm{C}$. The obtained extracts are weighted to determine the yield percentage (wt). In separator, a temperature and a pressure are supported within $20^{\circ} \mathrm{C}$ and 5 bar being optimum for separation of an extract from gaseous $\mathrm{CO}_{2}$. The extraction time $(2 \mathrm{~h})$, a rate of $\mathrm{SC} \mathrm{CO}_{2}$ flow $(1.5 \pm 0.05 \mathrm{~kg} / \mathrm{h})$, and temperature $\left(50{ }^{\circ} \mathrm{C}\right)$ are constant for all processes. Set parameters provide a total extraction for every process.

\subsection{Compositional analysis of (SFE) extracts}

The compositional analysis of extracts obtained was carried out using Shimadzu GCMS-QP2010 plus chromatograph-mass spectrometer in Supelco SLB TM-5 ms column $(30 \mathrm{~m} \times 0.25 \mathrm{~mm} \times 0.25 \mu \mathrm{m})$ in "split" mode. High-purity helium (99.9999\%) with a flow rate of $1 \mathrm{~mL} \mathrm{~min}^{-1}$ was used as a carrier gas. The column temperature was raised from $60^{\circ} \mathrm{C}$ (the hold time was $4 \mathrm{~min}$ ) to $150^{\circ} \mathrm{C}$ at a rate of $10^{\circ} \mathrm{C} /$ min after that up to $280^{\circ} \mathrm{C}$ at a rate of $5^{\circ} \mathrm{C} / \mathrm{min}$. The temperature of an injector was $280^{\circ} \mathrm{C}$, an interface, and a detector was $250^{\circ} \mathrm{C}$. The ionization was performed by an electron impact with electron energy of $70 \mathrm{eV}$. The cathode emission current was $150 \mu \mathrm{A}$, a range of recorded ions was $45-500 \mathrm{~m} / \mathrm{z}$. The identification of components was performed by means of NIST08 and FFNSC mass-spectra libraries. Before analysis, a test portion was diluted in $\mathrm{n}$-hexane by a factor of $500.1 \mathrm{~mL}$ of diluted test portion was injected with split of 1:40 [21].

\subsection{Hydrodistillation}

$100 \mathrm{~g}$ of air-dried D. carota subsp. maritimus aerial parts were subjected to a hydrodistillation process during $2 \mathrm{~h}$, using a Clevenger-type apparatus. The essential oil was collected, dehydrated using anhydrous sodium sulphate and stored in hermitically sealed glass container at low temperature $\left(-5^{\circ} \mathrm{C}\right)$ until analysis. 


\subsection{GC-FID and GC-MS analyses of essential oil extracted by hydrodistillation}

GC analyses of the extracts were performed using a gas chromatograph (Agilent 7890A, Palo Alto, CA, USA), equipped with a $30 \mathrm{~m} \times 0.25 \mathrm{~mm}$ i.d. with $0.25 \mu \mathrm{m}$ stationary film thickness HP-5 capillary column (Agilent J\&W) and a flame ionization detector (FID). The following temperature program was used: from $60^{\circ} \mathrm{C}$ to $246{ }^{\circ} \mathrm{C}$, at a rate of $3{ }^{\circ} \mathrm{C} / \mathrm{min}$ and then held at $246^{\circ} \mathrm{C}$ for $20 \mathrm{~min}$ (total analysis time $82 \mathrm{~min}$ ). Other operating conditions are the following: carrier gas helium (purity $\geq 99.9999 \%$ - Air Liquide Italy); flow rate, $1.0 \mathrm{~mL} \mathrm{~min}^{-1}$; injector temperature, $250^{\circ} \mathrm{C}$; detector temperature, $300^{\circ} \mathrm{C}$. Injection of $1 \mu \mathrm{L}$ of diluted sample (1:100 in hexane, $\mathrm{w} / \mathrm{w})$ was performed with 1:10 split ratio, using an autosampler (Agilent, Model 7683B). GC-MS analyses were carried out using a gas chromatograph (Agilent 6890N) equipped with a $30 \mathrm{~m} \times 0.25 \mathrm{~mm}$ i.d. with $0.25 \mu \mathrm{m}$ stationary film thickness HP- 5 ms capillary column (Agilent J\&W) coupled with a mass selective detector having an electron ionization device, EI, and a quadrupole analyzer (Agilent 5973). The temperature program was the same used for GC. Other chromatographic operating conditions are the following: carrier gas helium (purity $\geq 99.9999 \%$ ); flow rate $1.0 \mathrm{~mL} \mathrm{~min}^{-1}$; injector temperature, $250^{\circ} \mathrm{C}$. Injection of $1 \mu \mathrm{L}$ of diluted sample (1:100 in hexane, w/w) was performed with 1:20 split ratio, using an auto sampler (Agilent, Model 7683B). The MS conditions were as follows: MS transfer line temperature, $240^{\circ} \mathrm{C}$; EI ion source temperature, $200^{\circ} \mathrm{C}$ with ionization energy of $70 \mathrm{eV}$; quadrupole temperature, $150{ }^{\circ} \mathrm{C}$; scan rate, $3.2 \mathrm{scan} \mathrm{s}^{-1}$ at $\mathrm{m} / \mathrm{z}$ scan range: (30 to 480 ). To handle and process chromatograms and mass spectra was used the software MSD ChemStation (Agilent, rev. E.01.00.237).

Constituents of the samples were identified by comparing: mass spectra fragmentation patterns with those of a computer library [22,23] and linear retention indices (RI) based on a homologous series of $\mathrm{C}_{8}-\mathrm{C}_{26} \mathrm{n}$-alkanes with those reported in literature (Stein et al., 2008). The Table 2 shows the chromatographic results, expressed as GC peak area percentages.

\section{Results and discussion}

\subsection{Effect of pressure variation on the extraction yield}

The technology of the supercritical carbon dioxide is considered as one of the most potentially useful new methods suitable for essential oils extraction of better quality [24]. In this study, we intend to study the behavioral changes in the yields and the quality of wild $D$. carota subsp. maritimus essential oils obtained by hydrodistillation and supercritical fluid carbon dioxide under appropriate conditions of temperature and pressure. The variation of the yields of extractive substances derived from successive supercritical fluid extraction from one and same raw material at 100 and 300 bar and a constant temperature of $50{ }^{\circ} \mathrm{C}$ are presented in Fig. 2. Similar trends were described previously and reported that extraction yield enhanced significantly with increase of pressure at a constant temperature, due to an increase of the solubility [3]. In fact, the reduction of the surface between $\mathrm{CO}_{2}$ molecules, increases its density and the contact surface between the extractable compounds and the extraction solvent [3]. Moreover, we noticed a significant difference in the quantity of the essential oil recovered by hydrodistillation compared to the innovative SFE procedure (Fig. 2). The yield of extractable organic volatiles from $D$. carota subsp. maritimus obtained using conventional hydrodistillation was more than seven times lower than that of the extraction achieved via supercritical fluid presenting a better selectivity for components of interest.

\subsection{Effect of pressure variation on the supercritical fluid extractive substances}

Data on the compositional analysis of both essential oils obtained by sequential SFE processes are presented in Table 1. The experiment

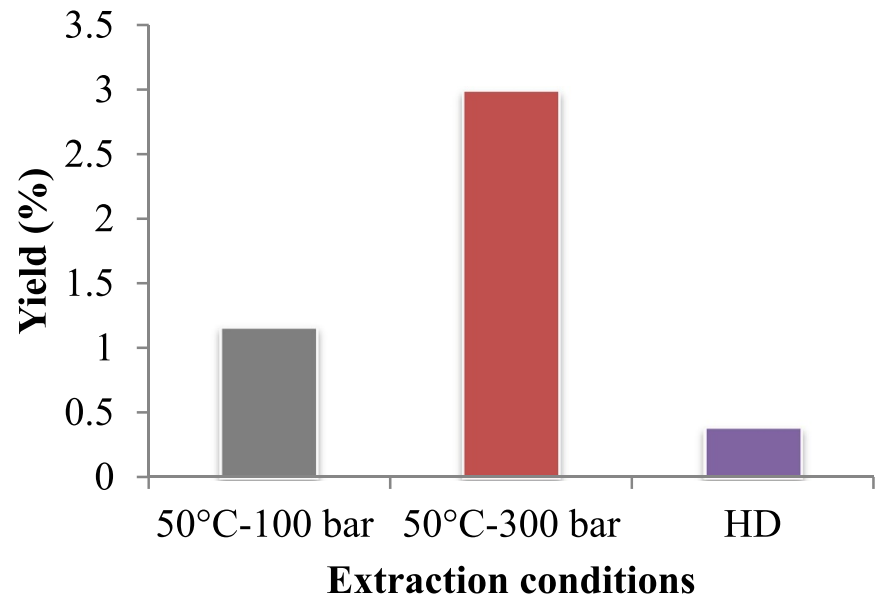

Fig. 2. Comparison of SFE and hydrodistillation yields of $D$. carota subsp. maritimus essential oil.

consisted on a first 120 min extraction at 100 bar as described in section 2.3 , to remove mainly the essential oil preferentially extracted at low pressure followed by a second extraction at 300 bar applied on same raw material. Thus, a total of 35 organic volatiles, representing $92.7 \%$ of the whole constituents, were identified in the essential oil derived by $\mathrm{SC} \mathrm{CO}_{2}$ at 100 bar, whereas the $\mathrm{SC} \mathrm{CO}_{2}$ extract obtained at $300 \mathrm{bar}$ revealed the presence of 60 compounds, 32 of which were identified and $45.31 \%$ of constituents were unidentified. Out of the 35 compounds detected at $100 \mathrm{bar}, 10$ were quantified in low percentages $(0.06-1.71 \%)$, and were completely absent at 300 bar. Out of the 32 compounds, 8 were detected only in the oil extracted at 300 bar, among them; $\alpha$-bisabolol reached $1.53 \%$.

In order to compare the quality of $D$. carota subsp. maritimus essential oil extracted at 100 to that of the extract derived at 300 bar, the percentages of the main compounds are depicted in Fig. 3. The oxygenated monoterpene, geranyl acetate, identified as the chemotype and most beneficial ingredient from $D$. carota subsp. maritimus, was abundant at a higher percentage of $26.43 \%$ in the essential oil obtained at 100 bar comparing to that of the derived extract prepared at $300 \mathrm{bar}$ (12.85\%). Moreover, the others main compounds constituting the essential oil extracted at 100 bar are $\beta$-bisabolene $(20.39 \%)$ and elemicin $(8.26 \%)$, those constituents were less abundant and detected at only $11.53 \%$ and $5.35 \%$ in the extract obtained at 300 bar (Fig. 4).

The significant variability in the amounts of the main chemical classes in both extracts should be highlighted (Fig. 5). We noticed that the low molecular weight compounds (monoterpenes) were already obtained at 100 bar $(43.36 \%)$, their percentage in the extract derived at 300 bar regularly decreased up to $18.26 \%$.It is apparent from the obtained results that the increase in pressure from 100 to 300 bar led to a decrease in the percentage of sesquiterpenes hydrocarbons from $31.36 \%$ to $15.53 \%$, in contrast the amount of oxygenated sesquiterpenes slightly increased ( $4 \%$ for 100 bar and $7.48 \%$ for 300 bar). Moreover, the higher concentration of phenyl derivatives found at low pressure (100 bar) with a percentage reaching up to $14.05 \%$ and they are less abundant at 300 bar (11.31\%).

Previous researches revealed that pressure can significantly influence essential oil yield and their chemical constituents. This outcome was in agreement with the study of Donelian et al. [25] which noted that the pressure is a predominant factor in the variation in the concentration of the principal components of the patchouli essential oil.

Aliev et al. [21], also, reported that the increase of the oxygenated sesquiterpenes in the extract obtained at 300 bar was due to the solvent permeation into the deeper cellular structure of the raw material by virtue of pressure rise and the extraction of hard-to-get oils.

Consequently, it was verified that, depending on the pressure condition of $\mathrm{SCCO}_{2}$, it is possible to obtain an essential oil of high quality. 
Table 1

Compositional analysis of extracts from $D$. carota subsp. maritimus derived at 100 and 300 bar.

\begin{tabular}{|c|c|c|c|c|}
\hline \multirow[t]{2}{*}{ Compounds } & \multirow[t]{2}{*}{ Ret. Time } & \multicolumn{2}{|c|}{ Area of peak (\%) } & \multirow[t]{2}{*}{$m / z$} \\
\hline & & $50{ }^{\circ} \mathrm{C}-100$ bar & $50{ }^{\circ} \mathrm{C}-300$ bar & \\
\hline$\alpha$-Pinene & 8.393 & 4.82 & 1.06 & TIC \\
\hline Camphene & 8.869 & 0.11 & - & TIC \\
\hline Sabinene & 9.469 & 4.20 & 1.12 & TIC \\
\hline$\beta$-Pinene & 9.617 & 2.51 & 0.68 & TIC \\
\hline Myrcene & 9.853 & 1.33 & 0.38 & TIC \\
\hline Limonene & 10.859 & 0.90 & 0.28 & TIC \\
\hline (E)- $\beta$-ocimene & 11.202 & 0.12 & - & TIC \\
\hline$\alpha$-Campholenic aldehyde & 12.901 & 0.14 & - & TIC \\
\hline trans-Pinocarveol & 13.227 & 0.24 & 0.21 & TIC \\
\hline trans-Verbenol & 13.297 & 0.53 & 0.47 & TIC \\
\hline Pinocarvone & 13.601 & 0.20 & 0.13 & TIC \\
\hline Terpinen-4-ol & 13.910 & - & 0.05 & TIC \\
\hline Myrtenal & 14.191 & 0.30 & 0.26 & TIC \\
\hline Verbenone & 14.406 & 0.26 & 0.18 & TIC \\
\hline trans-Carveol & 14.545 & 0.06 & - & TIC \\
\hline Carvone & 14.962 & 0.77 & - & TIC \\
\hline Geraniol & 14.974 & - & 0.59 & TIC \\
\hline Bornyl acetate & 15.582 & 0.18 & - & TIC \\
\hline$\alpha$-Terpinyl acetate & 16.553 & 0.11 & - & TIC \\
\hline Neryl acetate & 16.636 & 0.15 & - & TIC \\
\hline$\alpha$-Longipinene & 16.769 & 2.38 & 0.94 & TIC \\
\hline Geranyl acetate & 16.991 & 26.43 & 12.85 & TIC \\
\hline$\beta$-Elemene & 17.336 & 0.28 & 0.11 & TIC \\
\hline (E)-Caryophyllene & 17.954 & 2.56 & 1.12 & TIC \\
\hline Bicyclogermacrene & 18.008 & - & 0.55 & TIC \\
\hline$r$-Elemene & 18.009 & 1.12 & - & TIC \\
\hline Sesquisabinene & 18.153 & 0.29 & 0.12 & TIC \\
\hline$(E)-\beta$-Farnesene & 18.258 & 0.31 & 0.14 & TIC \\
\hline$\alpha$-Humulene & 18.570 & 0.65 & 0.38 & TIC \\
\hline Vanillin methyl ether & 18.769 & - & 0.32 & TIC \\
\hline Methyl isoeugenol & 19.054 & 2.72 & 1.91 & TIC \\
\hline$\alpha$-Bulnesene & 19.172 & 1.34 & 0.64 & TIC \\
\hline$\beta$-Bisabolene & 19.348 & 20.39 & 11.53 & TIC \\
\hline Germacrene B & 19.608 & 0.34 & - & TIC \\
\hline Elemicin & 19.936 & 8.26 & 5.35 & TIC \\
\hline$\alpha$-Elemol & 20.149 & - & 0.12 & TIC \\
\hline Caryophyllene oxide & 20.916 & 0.96 & 0.68 & TIC \\
\hline cis-Thujopsene & 22.208 & 1.70 & - & TIC \\
\hline$\alpha$-Bisabolol & 22.210 & - & 1.53 & TIC \\
\hline Asarone & 22.318 & 3.07 & 3.73 & TIC \\
\hline Juniper camphor & 23.089 & 3.04 & 5.15 & TIC \\
\hline n-Hexadecanoic acid & 27.746 & - & 1.41 & TIC \\
\hline n-triacontane & 39.901 & - & 0.70 & TIC \\
\hline \multicolumn{2}{|c|}{ Monoterpenes hydrocarbons } & 13.99 & 3.52 & \\
\hline \multicolumn{2}{|l|}{ Oxygenated monoterpenes } & 29.37 & 14.74 & \\
\hline \multicolumn{2}{|c|}{ Sesquiterpenes hydrocarbons } & 31.36 & 15.53 & \\
\hline \multicolumn{2}{|c|}{ Oxygenated sesquiterpenes } & 4 & 7.48 & \\
\hline \multicolumn{2}{|l|}{ Phenyl derivatives } & 14.05 & 11.31 & \\
\hline \multicolumn{2}{|l|}{ Other } & - & 2.11 & \\
\hline \multicolumn{2}{|l|}{ Total identified (\%) } & 92.77 & 54.69 & \\
\hline \multicolumn{2}{|l|}{ Total unidentified (\%) } & 6.92 & 45.31 & \\
\hline
\end{tabular}

-: absent.

The percentages of major odorants constituting the essential oils are represented on bold.

\subsection{Comparison of supercritical fluid extraction with the hydrodistilled essential oil}

The present study constitutes also a good opportunity to compare the qualities of $D$. carota subsp. maritimus extracted by different techniques. Thus, the chemical composition of the aerial parts essential oil obtained by hydrodistillation is reported in Table 2. As a result, we noticed that carbon dioxide extracts were closer in chemical composition to the hydrodistilled essential oil characterised similarly by its specific richness in the oxygenated monoterpene odorant geranyl acetate (29\%). All analyzed essential oils contained almost the same constituents. However the supercritical fluid extracts presented the highest numbers of organic volatiles than the hydrodistillate. Thus, It

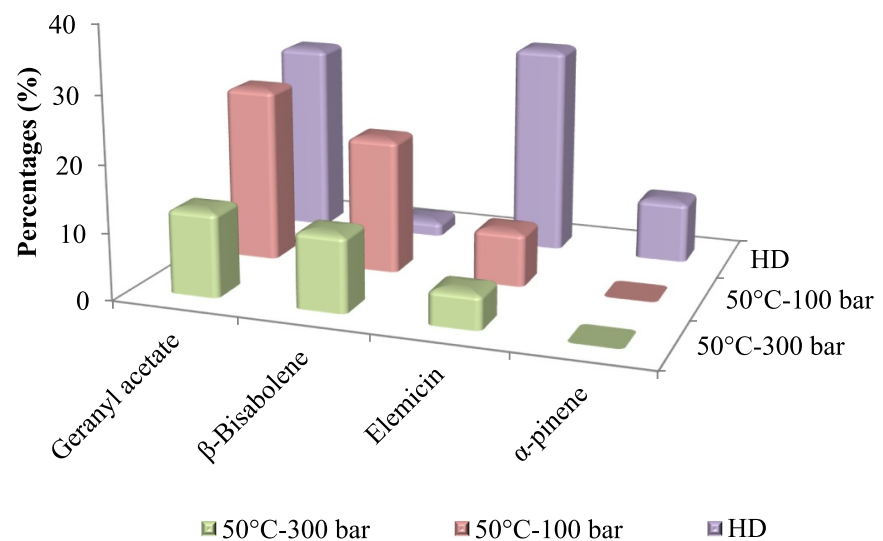

Fig. 3. Relative extraction efficiencies of representative Essential oil components from $D$. carota subsp. maritimus based on hydrodistillation and supercritical fluid extraction.
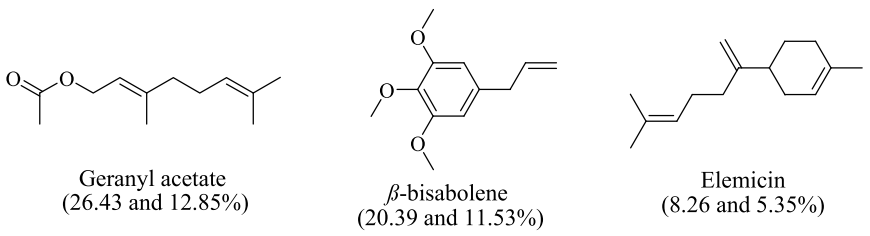

Fig. 4. Major constituents of $D$. carota subsp. maritimus SC $\mathrm{CO}_{2}$ extracts.

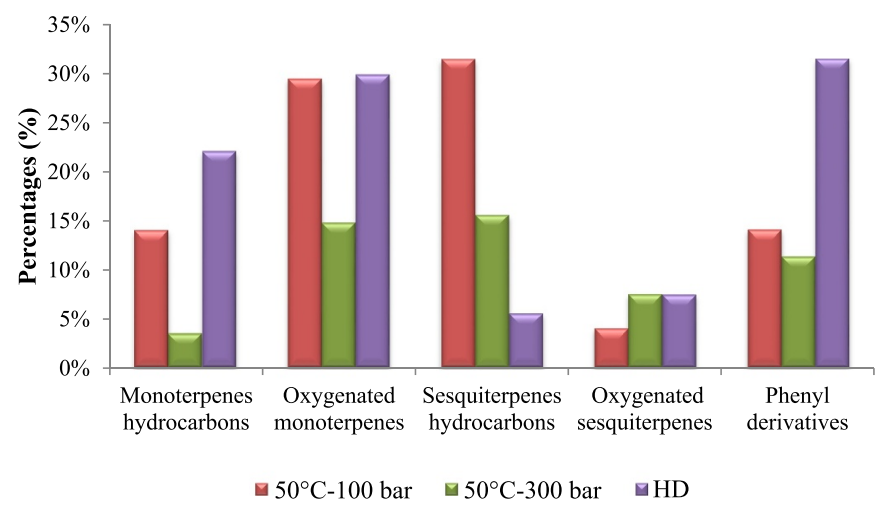

Fig. 5. Effect of extraction technique on D. carota subsp. maritimus chemical classes.

can be postulated that some compounds (as myrtenal, verbenone and some sesquiterpene hydrocarbons) were thermally degraded by hydrodistillation. Therefore, the investigations showed some differences in the quantities and nature of the detected components with respect to the type of extraction technique. Hydrodistillation process is more suitable for extracting Monoterpenes hydrocarbons (22\%), oxygenated monoterpenes $(29.8 \%)$ and phenyl derivatives $(31.4 \%)$, while supercritical carbon dioxide can be useful as a selective procedure to extract sesquiterpenes hydrocarbons (Fig. 5). In fact, a biggest number of sesquiterpenes hydrocarbons, dominated by $\beta$-bisabolene, was efficiently extracted by means of SFE. Moreover, $\beta$-bisabolene abundant at $20.39 \%$ in the SFE essential oil prepared at $\left(50^{\circ} \mathrm{C}-100 \mathrm{bar}\right)$ was extracted at a substantially lower percentage (2.4\%) using hydrodistillation (Fig. 3). This important odorant, shows interesting anti-tumor properties against melanoma, hepatocellular carcinoma and leukemia cells [26]. Moreover, previous studies have reported the importance of Elemicin because of its antibacterial [27], antifungal, anti-cholinergic [1], antioxidant [28], anti-inflammatory, antiviral and analgesic [29] activities. 
Table 2

Chemical compositions of Daucus carota subsp. maritimus hydrodistilled essential oil (\%).

\begin{tabular}{|c|c|c|c|c|}
\hline Number & Compound & $\mathrm{RI}^{\mathrm{a}}$ & $\% \mathrm{RA}^{\mathrm{b}}$ & Identification $^{c}$ \\
\hline 1 & $\alpha$-Thujene & 929 & 0.1 & RI,MS \\
\hline 2 & $\alpha$-Pinene & 937 & 9.4 & RI,MS \\
\hline 3 & CAMPHENE & 952 & 0.2 & RI,MS \\
\hline 4 & SABINENE & 976 & 1.7 & RI,MS \\
\hline 5 & $\beta$-Pinene & 979 & 4.4 & RI,MS \\
\hline 6 & Myrcene & 991 & 4.9 & RI,MS \\
\hline 7 & Ortho-cymene & 1026 & 0.1 & RI,MS \\
\hline 8 & SYLVESTRENE & 1031 & 1.2 & RI,MS \\
\hline 9 & LINALOOL & 1099 & 0.4 & RI,MS \\
\hline 10 & Terpinen-4-ol & 1178 & 0.2 & RI,MS \\
\hline 11 & Bornyl acetate & 1285 & $\operatorname{tr}$ & RI,MS \\
\hline 12 & $\alpha$-Longipinene & 1350 & 0.4 & RI,MS \\
\hline 13 & Geranyl acetate & 1386 & 29.0 & RI,MS \\
\hline 14 & $\beta$-Caryophyllene & 1418 & 1.1 & RI,MS \\
\hline 15 & $\alpha$-Humulene & 1452 & 0.2 & RI,MS \\
\hline 16 & $\gamma$-Muurolene & 1479 & 0.4 & RI,MS \\
\hline 17 & Ar-curcumene & 1481 & $\operatorname{tr}$ & RI,MS \\
\hline 18 & $\gamma$-Curcumene & 1484 & 0.4 & RI,MS \\
\hline 19 & $\beta$-Selinene & 1492 & 0.4 & RI,MS \\
\hline 20 & (E)-methyl isoeugenol & 1497 & 0.2 & RI,MS \\
\hline 21 & $\beta$-Bisabolene & 1507 & 2.4 & RI,MS \\
\hline 22 & $\delta$-Cadinene & 1522 & 0.2 & RI,MS \\
\hline 23 & $\gamma$-Vetivene & 1536 & $\operatorname{tr}$ & RI,MS \\
\hline 24 & Elemicin & 1559 & 31.4 & RI,MS \\
\hline 25 & Eremoligenol & 1630 & 0.2 & RI,MS \\
\hline 26 & Cubenol & 1643 & 4.8 & RI,MS \\
\hline 27 & $\beta$-Eudesmol & 1648 & 0.2 & RI,MS \\
\hline 28 & Eudesm-7(11)-en-4-ol & 1691 & 2.2 & RI,MS \\
\hline $\begin{array}{l}\text { Monoterpenes } \\
\text { hydrocarbons }\end{array}$ & & 22 & & \\
\hline $\begin{array}{l}\text { Oxygenated } \\
\text { monoterpenes }\end{array}$ & & 29.8 & & \\
\hline $\begin{array}{l}\text { Sesquiterpenes } \\
\text { hydrocarbons }\end{array}$ & & 5.5 & & \\
\hline $\begin{array}{l}\text { Oxygenated } \\
\text { sesquiterpenes }\end{array}$ & & 7.4 & & \\
\hline Phenyl derivatives & & 31.4 & & \\
\hline Total identified (\%) & & 96.1 & & \\
\hline
\end{tabular}

The percentages of major odorants constituting the essential oils are represented on bold

a Retention index relative to n-alkanes on HP-5 capillary column.

b Relative area (peak area relative to the total peak area).

Identification: MS, comparison of mass spectra with MS libraries.

It is worth noting that three analyzed essential oils are predominantly composed of geranyl acetate $(29 \%, 26.43 \%$ and $12.85 \%$, in HDEO, SFE 100 bar and 300 bar, respectively). This main oxygenated monoterpene detected, is commonly used as a constituent in perfumes, soap industry and cosmetic due to its pleasant rose odor [30]. The published data indicated that geranyl acetate exhibits powerful pharmacological effects related to inflammation and pain-related processes, and antioxidant properties [31]. Moreover, many studies have demonstrated its excellent anti-Candida, its anti-fungal, anti-inflammatory properties and bactericidal effects against Campylobacter jejuni and Escherichia coli [32]. It can be seen from Table 3 that, the geranyl acetate representing the chemotype of Tunisian $D$. carota subsp. maritimus essential oils, was previously extracted from other Daucus carota subspecies from different origins including $D$. carota subsp. carota [33], D. carota subsp. gummifer [34,35] and D. carota subsp. major [14].

It is worth noting that screening of the literature on $D$. carota subsp. maritimus showed the lack of prior research studies on the chemical composition of its aerial parts essential oil. However, the comparison of the results of our study with the former research on essential oils extracted from different organs and using conventional hydrodistillation [15], demonstrated a considerable dissimilarity of the chemicals depending on the organ and on the region of collect. Therefore, sabinene $(51.6 \%)$ identified in previous studies, as the major odorant in fresh flowers essential oil extracted via hydrodistillation of $D$. carota subsp. maritimus collected in Kroussia region (Sousse, Tunisia) [15], is rarely detected in the aerial parts volatiles oils of same species collected in Monastir region (present study). Moreover, dillapiole (46.6\%), the predominant constituent of roots essential oil [15], is completely absent in three samples subject of this work.

\section{Conclusion}

The present study establishes, for the first time, the effect of pressure on the characteristics of supercritical carbon dioxide essential oils from Tunisian $D$. carota subsp. maritimus. The enhancement of extraction yield is observed as pressure is increased from 100 to 300 bar for which the maximum yield of $2.986 \%$ is reached. The extraction capacity of $\mathrm{CO}_{2}$ is a function of pressure at a constant temperature and it influences clearly the nature and the class of odorants. Our investigation showed that $D$. carota subsp. maritimus essential oils are predominated by bioactive geranyl acetate, $\beta$-bisabolene and elemicin quantified at a greater concentration at a pressure of $100 \mathrm{bar}$ and a temperature of $50^{\circ} \mathrm{C}$. Comparative analysis showed that the essential oils prepared by SFE and hydrodistillation techniques, are rather similar, containing quite the same dominant odorants. However, the supercritical fluid gave the best extraction yield and it was more selective towards sesquiterpenes hydrocarbons than hydrodistillation. Thus, $\mathrm{CO}_{2}$ supercritical fluid methodology is presented as a fast, innovative, cleaner, economical, green and efficient method suitable to extract natural bioactive compounds from aromatic and medicinal plants.

\section{Acknowledgements}

The authors thank the Ministry of Higher Education and Scientific Research of Tunisia for financial support.

\section{Funding sources}

None.

Table 3

Percentages of geranyl acetate of the essential oils from Daucus carota species, current and previous studies.

\begin{tabular}{|c|c|c|c|c|}
\hline Daucus carota species & Country or district & Method extraction & Plant organs & Geranyl acetate $(\%)$ \\
\hline $\begin{array}{l}\text { D. carota subsp. maritimus } \\
\text { [present work] }\end{array}$ & Tunisia & Supercritical extraction & Aerial parts & $\begin{array}{l}26.43 \text { (100 bar) } \\
12.85 \text { (300 bar) } \\
29.0 \text { ( } 2 \text { h HD })\end{array}$ \\
\hline D. carota [33] & Tunisia & Hydrodistillation & Mature seeds & 48.75 \\
\hline D. carota $[13]$ & Serbia & Hydrodistillation & Seeds & 53.2 \\
\hline D. carota $[34]$ & Vienna & Hydrodistillation & Fruits & 28.1 \\
\hline D. carota subsp. carota [26] & Portugal & Hydrodistillation & Umbels with ripe seeds & 65.0 \\
\hline D. carota subsp. gummifer [27] & Spain & Hydrodistillation & Fruits & $51.74-76.95$ \\
\hline D. carota subsp. gummifer [28] & Portugal & Hydrodistillation & Ripe umbels & 37.0 \\
\hline D. carota ssp. major $[14]$ & - & Hydrodistillation & Fruits & 34.2 \\
\hline
\end{tabular}




\section{Declaration of Competing Interest}

No conflict of interest to declare.

\section{References}

[1] S. Petrovic, M. Radenkovic, M. Milenkovic, M. Couladis, M. Pavlovic, M. Niketic Composition, antimicrobial, antiradical and spasmolytic activity of Ferula heuffelii Griseb. ex Heuffel (Apiaceae) essential oil, Food Chem. 130 (2012) 310-315, https://doi.org/10.1016/j.foodchem.2011.07.043.

2] J.P. Coelho, A.F. Cristino, P.G. Matos, A.P. Rauter, B.P. Nobre, R.L. Mendes, J.G. Barroso, A. Mainar, J.S. Urieta, J.M.N.A. Fareleira, H. Sovová, A.F. Palavra, Extraction of volatile oil from aromatic plants with supercritical carbon dioxide: experiments and modeling, Molecules 17 (2012) 10550-10573, https://doi.org/10. 3390/molecules170910550.

[3] E. Uquiche, N. Cirano, S. Millao, Supercritical fluid extraction of essential oil from Leptocarpha rivularis using $\mathrm{CO}_{2}$, Ind. Crop. Prod. 77 (2015) 307-314, https://doi. org/10.1016/j.indcrop.2015.09.001.

[4] L.T. Danh, L.N. Han, N. Duy, A. Triet, Comparison of chemical composition, antioxidant and antimicrobial activity of Lavender (Lavandula angustifolia L.) essentia oils extracted by supercritical $\mathrm{CO}_{2}$, hexane and Hydrodistillation, Food Bioprod. Technol. 6 (2012) 3481-3489, https://doi.org/10.1007/s11947-012-1026-Z.

[5] F.J. Sen, S. Santoyo, S. Cavero, L. Jaime, E. Iban, G. Reglero, Supercritical carbon dioxide extraction of compounds with antimicrobial activity from Origanum vulgare L.: determination of optimal extraction parameters, J. Food Prot. 69 (2006) 369-375.

[6] T. Fornari, G. Vicente, E. Vázquez, M.R. García-risco, G. Reglero, Isolation of essential oil from different plants and herbs by supercritical fluid extraction, J. Chromatogr. A 1250 (2012) 34-48, https://doi.org/10.1016/j.chroma.2012.04. 051.

[7] A.M. Aliev, G.K. Radjabov, G.V. Stepanov, Composition of extract of the Juniperus oblonga M. Bieb. fruits obtained by supercritical $\mathrm{CO}_{2}$ extraction, Russ. J. Phys. Chem. B. 7 (2013) 795-801, https://doi.org/10.1134/S1990793113070038.

[8] M. Gonny, P. Bradesi, J. Casanova, U. De Corse, E. Chimie, U.M.R. Cnrs, R. Sanguinaires, Identification of the components of the essential oil from wild Corsican Daucus carota L. using ${ }^{13}$ C-NMR spectroscopy, Flavour Fragr. J. 19 (2004) 424-433, https://doi.org/10.1002/ffj.1330.

[9] T.B. Ng, E.F. Fang, X. Li, Q. Lu, J.H. Wong, H. Guo, Carrot (Daucus carota) oils, essent, Oils in Food Preservation, Flavour and Safety, 2016, pp. 303-308, , https:// doi.org/10.1016/B978-0-12-416641-7.00034-1.

[10] M. El Amine Dib, N. Djabou, J. Desjobert, H. Allali, B. Tabti, A. Muselli, J. Costa, Characterization of volatile compounds of Daucus crinitus Desf. headspace solid phase microextraction as alternative technique to hydrodistillation, Chem. Cent. J. 4 (2010).

[11] M. Staniszewska, J. Kula, M. Wieczorkiewicz, D. Kusewicz, Essential oils of wild and cultivated carrots - the chemical composition and antimicrobial activity, J. Essent. Oil Res. 17 (2005) 579-583, https://doi.org/10.1080/10412905.2005.9699002.

[12] D. Mockute, O. Nivinskiene, The sabinene chemotype of essential oil of seeds of Daucus carota L. ssp. carota growing wild in Lithuania, J. Essent. Oil Res. 16 (2011) 37-41, https://doi.org/10.1080/10412905.2004.9698720.

[13] Z. Stojanovic, N. Đor, N. Radulovic, Volatiles of the Balkan endemic Daucus guttatus ssp. zahariadii and cultivated and wild-growing D. carota - a comparison study, Food Chem. 125 (2011) 35-43, https://doi.org/10.1016/j.foodchem.2010.08.028.

[14] E. Cosimi, P.L. Cioni, I. Molfetta, A. Braca, Essential-oil composition of Daucus carota ssp. major (Pastinocello carrot) and nine different commercial varieties of Daucus carota ssp. sativus fruits, Chem. Biodivers. 11 (2014) 1022-1033.

[15] A. Jabrane, H.B. Jannet, F. Harzallah-Skhiri, M. Mastouri, J. Casanova, Z. Mighri, Flower and root oils of the Tunisian Daucus carota L. ssp. maritimus (Apiaceae): integrated analyses by GC, GC/MS, and ${ }^{13} \mathrm{C}-\mathrm{NMR}$ spectroscopy, and in vitro antibacterial activity, Chem. Biodivers. 6 (2009) 881-889, https://doi.org/10.1002/ cbdv.200800144.

[16] P. Alapetite, Flore de la Tunisie: Angiospermes-dicotylédones. 1, Apétalesdialypétales, Gamopétales 2 (1979) 618-619.

[17] S.B. Glišic, D.R. Mišic, M.D. Stamenić, I.T. Zizovic, R.M. Ašanin, D.U. Skala, Supercritical carbon dioxide extraction of carrot fruit essential oil: chemical composition and antimicrobial activity, Food Chem. 105 (2007) 346-352, https://doi org/10.1016/j.foodchem.2006.11.062.

[18] A. Snene, C. Sirignano, D. Rigano, C. Formisano, R. El Mokni, G. Ercolano, H. Dhaouadi, A. Ianaro, S. Hammami, O. Taglialatela-scafati, Antiproliferative metabolites from the Northern African endemic plant Daucus virgatus (Apiaceae),
Phytochemistry 143 (2017) 194-198, https://doi.org/10.1016/j.phytochem.2017. 08.010.

[19] A. Snene, R. El Mokni, H. Jmii, I. Jlassi, H. Jaïdane, D. Falconieri, A. Piras, H. Dhaouadi, S. Porcedda, S. Hammami, In vitro antimicrobial, antioxidant and antiviral activities of the essential oil and various extracts of wild (Daucus virgatus (Poir.) Maire) from Tunisia, Ind. Crop. Prod. 109 (2017) 109-115, https://doi.org/ 10.1016/j.indcrop.2017.08.015.

[20] A.M. Aliev, I.M. Abdulagatov, The study of microalgae Nannochloropsis salina fatty acid compositions extraction using different techniques. SCF vs conventional extraction, J. Mol. Liq. 239 (2017) 96-100, https://doi.org/10.1016/j.molliq.2016. 08.021.

[21] A.M. Aliev, G.K. Radjabov, A.M. Musaev, Dynamics of supercritical extraction of biological active substances from the Juniperus communis var. saxatillis, J. Supercrit. Fluids 102 (2015) 66-72, https://doi.org/10.1016/j.supflu.2015.04.009.

[22] R.P. Adams, Identification of Essential Oil Components by Gas Chromatography/ Mass Spectorscopy, Allured Pub. Corp, 2007.

[23] S.E. Stein, A. Mikaia, E. White, V. Zaikin, D. Zhu, B. Milman, V. Babushok, I. Zenkevich, P. Linstrom, Y. Mirokhin, D. Tchekhovskoi, W.G. Mallard, O.D. Sparkman, J.A. Sparkman, NIST Standard Reference Database 1A NIST/EPA/ NIH Mass Spectral Library (NIST 08) and NIST Mass Spectral Search Program (Version 2.0f) for Use with Microsoft ${ }^{\circledR}$ Windows User's Guide the NIST Mass Spectrometry Data Center, (2008).

[24] A. Akram, A. Younis, G. Akhtar, K. Ameer, A. Farooq, M.A. Hanif, M. Saeed, K. Lim, Comparative efficacy of various essential oil extraction techniques on oil yield and quality of Jasminum sambac L, Sci. Int. 5 (2017) 84-95, https://doi.org/10.17311/ sciintl.2017.84.95.

[25] A. Donelian, L.H.C. Carlson, T.J. Lopes, R.A.F. Machado, Comparison of extraction of patchouli (Pogostemon cablin) essential oil with supercritical $\mathrm{CO}_{2}$ and by steam distillation, J. Supercrit. Fluids 48 (2009) 15-20, https://doi.org/10.1016/j.supflu 2008.09.020.

[26] V.P. da Silvaa, C.C.F. Alvesa, M.L.D. Mirandab, L.C. Bretanhac, M.P. Ballestec, G.A. Mickec, E.V. Silveirac, C.H.G. Martinsd, M.A.L.V. Ambrosiod, T. de Souza Silvad, D.C. Tavaresc, L.G. Magalhãesc, F.G. Silvaa, M.B. Egeaa, Chemical composition and in vitro leishmanicidal, antibacterial and cytotoxic activities of essential oils of the Myrtaceae family occurring in the Cerrado biome, Ind. Crop. Prod. 123 (2018) 638-645, https://doi.org/10.1016/j.indcrop.2018.07.033.

[27] P.G. Rossi, L. Bao, A. Luciani, J. Panighi, J.M. Desjobert, J. Costa, J. Casanova, J.M. Bolla, L. Berti, (E)-Methylisoeugenol and elemicin: antibacterial components of Daucus carota L. essential oil against Campylobacter jejuni, J. Agric. Food Chem. 55 (2007) 7332-7336, https://doi.org/10.1021/jf070674u.

[28] A. Zardi-bergaoui, S. Jelizi, G. Flamini, R. Ascrizzi, H. Ben Jannet, Comparative study of the chemical composition and bioactivities of essential oils of fresh and dry seeds from Myoporum insulare R. Br, Ind. Crop. Prod. 111 (2018) 232-237, https:// doi.org/10.1016/j.indcrop.2017.10.019.

[29] Q. Wu, W. Wang, X. Dai, Z. Wang, Z. Shen, H. Ying, C. Yu, Chemical compositions and anti-influenza activities of essential oils from Mosla dianthera, J. Ethnopharmacol. 139 (2012) 668-671, https://doi.org/10.1016/j.jep.2011.11.056.

[30] G.R. Smitha, V.S. Rana, Variations in essential oil yield, geraniol and geranyl acetate contents in palmarosa (Cymbopogon martinii, Roxb. Wats. var. motia) influenced by inflorescence development, Ind. Crop. Prod. 66 (2015) 150-160, https:// doi.org/10.1016/j.indcrop.2014.12.062.

[31] S.A. Khayyat, M.Y. Sameeh, Bioactive epoxides and hydroperoxides derived from naturally monoterpene geranyl acetate, Saudi Pharm. J. 26 (2018) 14-19, https:// doi.org/10.1016/j.jsps.2017.11.005.

[32] M.J. Gonc, M. Teresa, A. Cristina, C. Cavaleiro, M. Celeste, J. Canhoto, L. Salgueiro, Composition and Biological Activity of the Essential Oil from Thapsia minor, a New Source of Geranyl Acetate, 35 (2012), pp. 166-171, https://doi.org/10.1016/j. indcrop.2011.06.030.

[33] A. Maxia, B. Marongiu, A. Piras, S. Porcedda, E. Tuveri, M.J. Gonçalves, C. Cavaleiro, L. Salgueiro, Chemical characterization and biological activity of essential oils from Daucus carota L. subsp. carota growing wild on the Mediterranean coast and on the Atlantic coast, Fitoterapia 80 (2009) 57-61, https://doi.org/10. 1016/j.fitote.2008.09.008

[34] M.G. Pinilla, M.J. Pérez-alonso, A. Velasco-negueruela, Volatile constituents from fruits of Daucus carota L., subsp. Gummifer hooker fil, J. Essent. Oil Res. 7 (1995) 433-435, https://doi.org/10.1080/10412905.1995.9698556.

[35] J. Valente, M. Zuzarte, R. Resende, M.J. Gonçalves, C. Cavaleiro, C.F. Pereira, M.T. Cruz, L. Salgueiro, Daucus carota subsp. gummifer essential oil as a natural source of antifungal and anti-inflammatory drugs, Ind. Crop. Prod. 65 (2015) 361-366, https://doi.org/10.1016/j.indcrop.2014.11.014. 